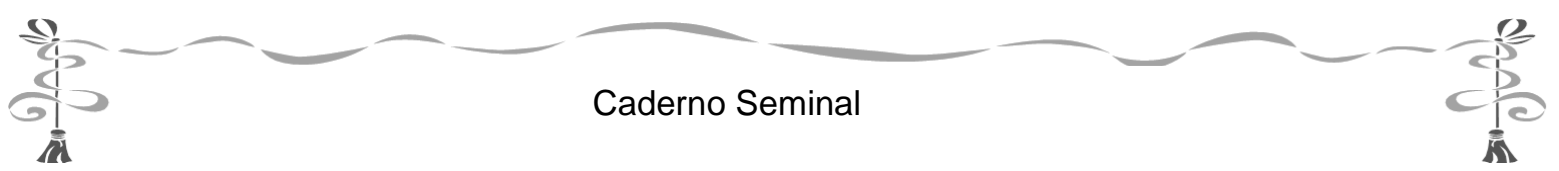

\title{
SOBRE O ENSINO DA TRADUÇÃO DAS EXPRESSÕES IDIOMÁTICAS: ALGUMAS REFLEXÕES ${ }^{21}$
}

\author{
ON TEACHING THE TRANSLATION OF IDIOMATIC EXPRESSIONS: SOME REFLECTIONS
}

Liliane Santos 22

\section{Resumo}

Enquanto expressões convencionais, cristalizadas tanto linguística como culturalmente, os idiomatismos constituem formas cujos significado e sentido não podem ser calculados pela simples conjunção do léxico com a gramática. Esse fator, somado ao fato de o seu uso estar estreitamente ligado à situação de enunciação, explica por que essas expressões representam uma das maiores dificuldades que enfrentam professores e aprendizes de uma língua estrangeira. Neste trabalho, apresentamos algumas observações a respeito da elaboração de uma metodologia de ensino para a tradução das expressões idiomáticas, classificando-as em quatro categorias: (i) idênticas, (ii) parafraseáveis, (iii) reconhecíveis e (iv) intraduzíveis. Essas categorias determinarão quatro diferentes estratégias de tradução.

Palavras-chave: Expressões idiomáticas, ensino de línguas, tradução.

\section{Abstract}

Being conventional and frozen expressions, both from linguistic and cultural points of view, idioms constitute a whole whose sense and meaning do not be constructed from the conjunction of lexicon and grammar. Coupled with the fact that their use is closely linked to the situation of enunciation, this factor explains why those expressions represent a major difficulty to teachers and learners of a foreign language. In this work, we present some observations on the development of a teaching methodology for the translation of these expressions, suggesting their classification into four categories: (i) identical, (ii) paraphrasable, (iii) recognizable, and (iv) untranslatable. We suggest, moreover, that these four categories correspond to four different translation strategies.

Key-Words: Idioms, language teaching, translation.

\section{Introdução}

Entre as maiores dificuldades com as quais se confrontam professores e aprendizes de uma língua estrangeira - e mais especificamente no caso do ensino/aprendizagem da tradução -, encontram-se as expressões idiomáticas (EI). Cristalizadas e indecomponíveis, com sentido e emprego determinados cultural e convencionalmente, as EI não somente estão estreitamente vinculadas à situação de enunciação, como também apresentam uma significação que não corresponde à soma dos significados individuais dos seus constituintes (ou seja, uma significação que não pode ser calculada simplesmente pela conjunção do léxico com a gramática). Neste sentido, é importante observar que

\footnotetext{
${ }^{21}$ Uma versão preliminar deste trabalho foi apresentada em Santos (2011).

${ }^{22}$ Université Charles-de-Gaulle - Lille 3 - UMR 8163 “Savoirs, Textes, Langage” (CNRS). liliane.santos@univ-lille3.fr
}

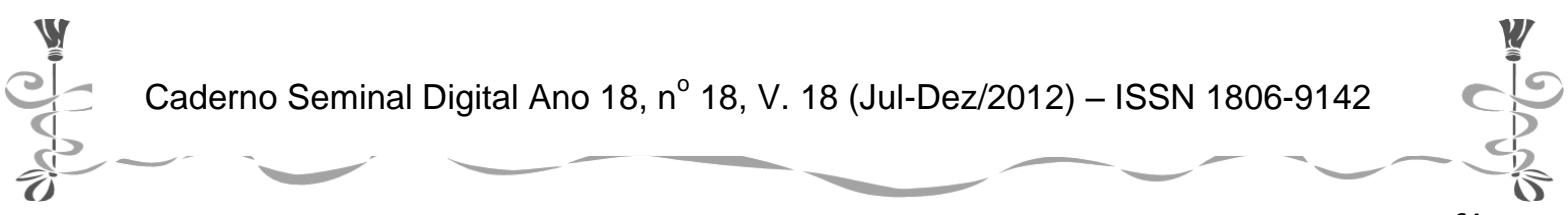




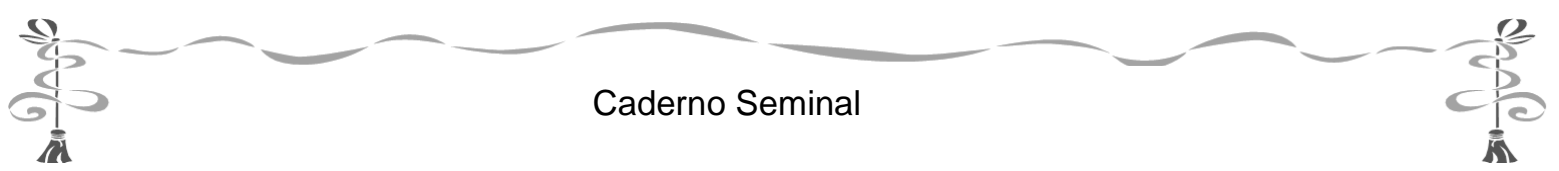

a aquisição da maioria das combinações idiomáticas se faz de forma não sistemática, em leituras ou conversas, desde que o falante esteja atento a elas. Além disso, esse indivíduo só perceberá que se trata de uma expressão consagrada quando a ouvir repetidas vezes. Então, poderá memorizá-las e utilizá-las quando a situação e o contexto as transformarem num fator específico de eficácia comunicacional (XATARA, 1995, p. 200).

Uma vez que o nosso objetivo é apresentar algumas observações sobre os elementos que consideramos necessários à elaboração de uma metodologia de trabalho no ensino da tradução das EI, convém observar que não nos ocuparemos da questão da sua aquisição. Apenas desejamos chamar a atenção para o fato de que o conjunto dos elementos acima delineados permite perceber por que razão o domínio das EI representa um capítulo à parte no ensino da tradução.

Iniciaremos nossa discussão por uma breve revisão da literatura a respeito dos idiomatismos ${ }^{23}$, de modo a estabelecer uma definição mais precisa do que a que acabamos de esboçar. Em segundo lugar, trataremos de questões ligadas à sua tradução e ao seu tratamento pelos estudos lexicográficos. Em terceiro lugar, discutiremos a problemática do lugar ocupado pelo estudo das EI no ensino de línguas, examinando, em quarto lugar, uma proposta de análise morfossintática e de classificação das EI numa perspectiva contrastiva. Em seguida, apresentaremos o nosso ponto de vista sobre a questão do ensino da tradução dessas expressões, apresentando também elementos que julgamos importante levar em conta quando da elaboração de uma metodologia de ensino para a tradução das EI. Nas nossas considerações finais, destacaremos os pontos mais importantes da nossa argumentação e abriremos a possibilidade de utilizar uma metodologia semelhante à que sugerimos para o ensino da tradução das EI para o ensino da tradução dos provérbios.

Tendo em vista o escopo deste trabalho, não aprofundaremos a discussão sobre os critérios de reconhecimento das EI, que daremos, em larga medida, por conhecidos. Também não trataremos dos critérios que permitem identificar e distinguir as diferentes unidades fraseológicas (colocação, locução, refrão, provérbio, expressão idiomática). Para uma discussão em profundidade sobre o assunto, remetemos aos trabalhos de Matias (2008) e Reis (2008), que apresentam, cada um, uma longa discussão a respeito dos critérios que permitem identificar e caracterizar uma expressão idiomática, assim como as demais unidades fraseológicas. Remetemos também a Xatara (2001), que apresenta o conjunto das sete "delimitações" às quais obedeceu a elaboração do seu Dictionnaire d'expressions idiomatiques Français-PortugaisFrançais ${ }^{24}$.

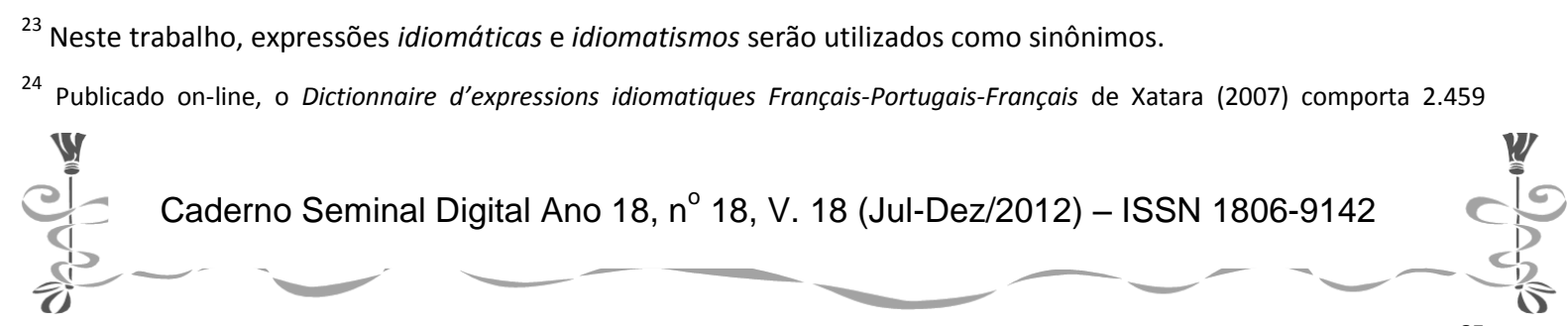




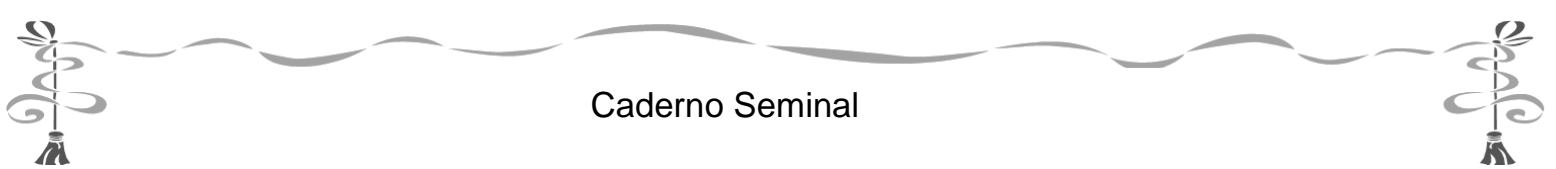

Por último, gostaríamos de fazer observar que, embora a maioria dos autores não se preocupe em estabelecer essa diferença ao tratar do estudo contrastivo de EI pertencentes a duas línguas, preferimos o termo correspondência ao termo equivalência, uma vez que, como indicam Riva \& Rios (2002, p. 7), este último "traz em sua etimologia a ideia de uma 'igualdade de valor', [o] que não (...) [corresponde ao] nosso objetivo".

\section{Expressões Idiomáticas: Definição}

Se durante muito tempo o estudo das expressões idiomáticas esteve excluído dos estudos linguísticos ${ }^{25}$, é em trabalhos mais recentes, interessados por questões semânticas, pragmáticas e discursivas, que vamos encontrar as primeiras tentativas de definição dessas lexias complexas. É o caso, por exemplo, de Chafe (1970), para quem os idiomatismos são estruturas que representam combinações de morfemas que não constituem unidades semânticas por si sós mas que, em conjunto, constituem uma nova unidade semântica. Nesse mesmo sentido, Caramori (2006, p. 49) sublinha o fato de que uma EI "não possui autonomia frástica completa", sublinhando também que a "a somatória do significado de cada palavra não corresponde ao sentido do todo".

De modo semelhante, ao discutir o problema da segmentação das unidades lexicais no discurso, Biderman (1978, p. 133) define os idiomatismos como "combinatórias de lexemas que o uso consagrou numa determinada sequência e cujo significado não é a somatória das suas partes" e, nessa mesma linha de pensamento, Tagnin (1988, p. 44) define como idiomáticas “aquelas expressões que não podem ser decodificadas literalmente, ou seja, cujo significado é convencionado, não resultando da somatória do significado de seus elementos". Em outro trabalho, e com o objetivo distinguir idiomaticidade de convencionalidade, essa mesma autora afirma que "uma expressão é idiomática apenas quando seu significado não é transparente, isto é, quando o significado da expressão toda não corresponde à somatória do significado de cada um de seus elementos" (Tagnin, 1989, p. 13, sublinhado pela autora) ${ }^{26}$.

Por sua parte, Reis (2008, pp. 20-21), acentuando a cristalização como característica definidora das EI, sublinha que "são expressões fixas, isso quer dizer que são

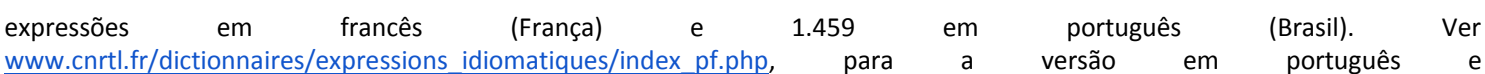
www.cnrtl.fr/dictionnaires/expressions idiomatiques, para a versão em francês (acesso99

em 4.dez.2009).

${ }^{25}$ De acordo com Xatara (1995, p. 196), isso se deve ao fato de que "tendo a língua (langue) permanecido por muito tempo o objeto da linguística, os idiomatismos foram automaticamente excluídos por pertencerem, a priori, à fala (parole)". Além disso, "por muito tempo a semântica e a pragmática foram marginalizadas, ciências essas imprescindíveis para o estudo das [expressões idiomáticas]".

${ }^{26}$ Para a autora, "toda expressão idiomática é também convencional, mas nem toda expressão convencional é idiomática. (...) Feliz Natal é convencional, porém não idiomática, pois seu sentido é transparente” (id., ibid.).
}

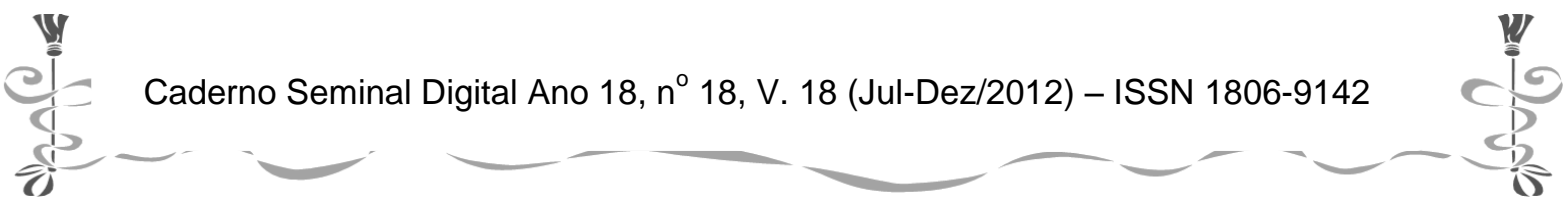




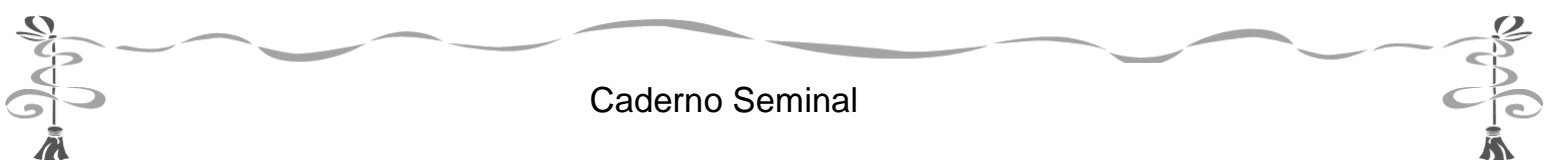

unidades lexicais que não admitem inserção, nem substituição por outros itens lexicais" e que "uma vez cristalizada, a EI não admite substituição de qualquer de suas palavras componentes".

Como se vê, essas definições destacam três traços característicos das EI:

(i) no plano lexical, o fato de constituírem uma unidade estável (fixa, cristalizada), pela combinação de morfemas/lexemas;

(ii) no plano sintático, o seu caráter indecomponível, aliado ao fato de não constituírem uma unidade frástica independente;

(iii) no plano semântico, uma significação opaca e que não corresponde à soma dos significados dos seus elementos constituintes.

A esse conjunto acrescentaremos dois outros traços característicos, apresentados de modo subjacente nas definições acima:

(iv) no plano pragmático, a relação estreita que entretêm com a situação de enunciação; e

(v) no plano cultural, a sua fixação e consagração pelo uso, além do fato de revelarem a visão de mundo própria a uma dada cultura.

E é justamente esse conjunto de cinco traços que Xatara \& Oliveira (2002, p. 57) utilizam para definir expressão idiomática:

toda lexia complexa indecomponível, conotativa e cristalizada em um idioma pela tradição cultural. Por isso, é uma unidade locucional ou frasal que constitui uma combinatória fechada, de distribuição única ou bastante restrita, e, desse modo, seus componentes não podem mais ser dissociados significando uma outra coisa, ou seja, sua interpretação semântica não pode ser calculada a partir da soma dos significados individuais de seus elementos.

Observe-se que é igualmente possível depreender dessa definição que o processo de cristalização das EI é o fator responsável pela sua estabilidade semântica, a qual, por sua vez, não somente possibilita a sua transmissão de geração em geração, mas permite justamente a sua consagração pela tradição cultural.

Tendo em vista as características linguístico-culturais das EI, acima apresentadas, o seu estudo constitui um problema de grande interesse para a tradução e, mais ainda, para o seu ensino. São esses os pontos que abordaremos a seguir, começando pelas questões ligadas à tradução.

\section{A Tradução das El: Estratégias E Lexicografia}

Sendo, como já indicamos, expressões cristalizadas, cujo sentido não é depreensível da soma dos sentidos dos elementos que as compõem, as EI representam o mais das vezes um sério problema para o tradutor, sendo, por esta razão, objeto da atenção de alguns estudiosos da área. Tagnin (1988, p. 44), por exemplo, ao analisar

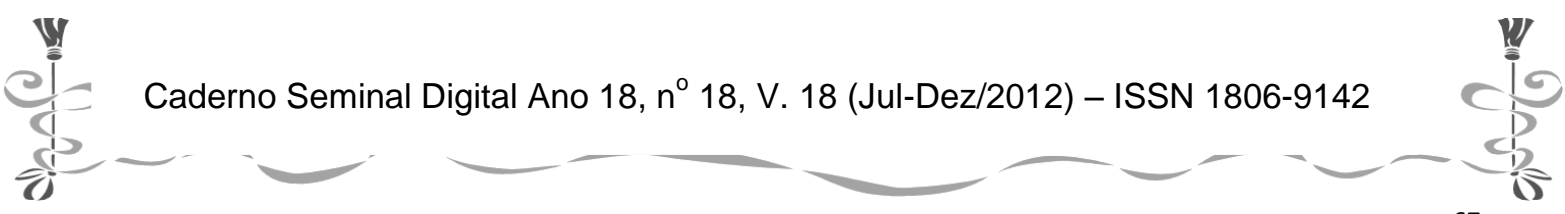




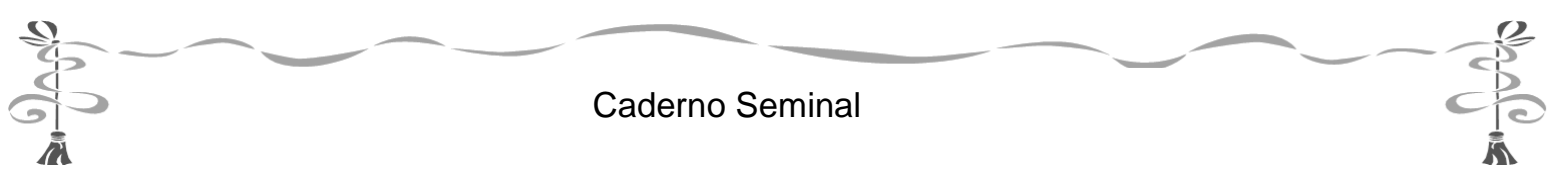

os idiomatismos culturais ${ }^{27}$, afirma que lhe "parece ser consenso que uma tradução deve perder o mínimo possível de informação do texto original”. Ela propõe, então, seis estratégias para a tradução dos idiomatismos culturais, indo da tradução literal ao uso de um “equivalente pragmático" (pp. 44-45, sublinhado pela autora):

1. manter a expressão na forma original;

2. manter a expressão na forma original acrescida de nota explicativa;

3. traduzir literalmente;

4. traduzir literalmente, acrescentando nota explicativa;

5. explicar a expressão no texto;

6. empregar um equivalente pragmático. (...)

Manter a expressão na forma original significa apenas transcrevê-la, como no caso de Halloween, por exemplo. O acréscimo, ou não, de uma nota explicativa dependerá do público a que se destina o texto. (...).

A tradução literal é uma tradução lexical, ou seja, cada item é traduzido pelo seu equivalente lexical na língua de chegada. Assim, "Labor Day" é traduzido por "Dia do Trabalho". No caso de não haver uma equivalência pragmática, far-se-á uma nota explicativa esclarecendo a diferença entre as duas culturas.

A explicitação se dá quando, ao invés de se traduzir uma expressão, sua explicação é incorporada ao texto.

O equivalente pragmático é aquele que é empregado numa mesma situação em culturas diferentes. Por exemplo, "Muito prazer" é o equivalente pragmático do inglês "How do you do?".

Xatara (1998), por sua vez, propõe que a tradução de uma EI inclua, além de uma definição (uma explicação da sua significação), a recuperação do seu valor metafórico. Trabalhando nesse sentido, Gonçalves \& Sabino (2001, p. 65), propõem traduções como as exemplificadas abaixo:

(1) Mettere il carro davanti ai buoi

(2) Fare il diavolo a quattro
Colocar o carro/a carroça na frente dos bois (equivalente); precipitar-se (explicação).

Fazer o diabo/fazer o diabo a quatro (equivalente); fazer grande balbúrdia, desordem (explicação).

O tratamento lexicográfico das EI consiste num outro domínio para o qual a questão da sua tradução é de extrema importância. De fato, diferentes questões colocam-se aos dicionaristas, entre as quais podemos, com Xatara (1995, p. 197), citar as seguintes:

27 Segundo Tagnin (id., ibid., sublinhado pela autora) "são idiomatismos exatamente por não poderem ser decodificados literalmente e culturais por transmitirem um dado cultural"

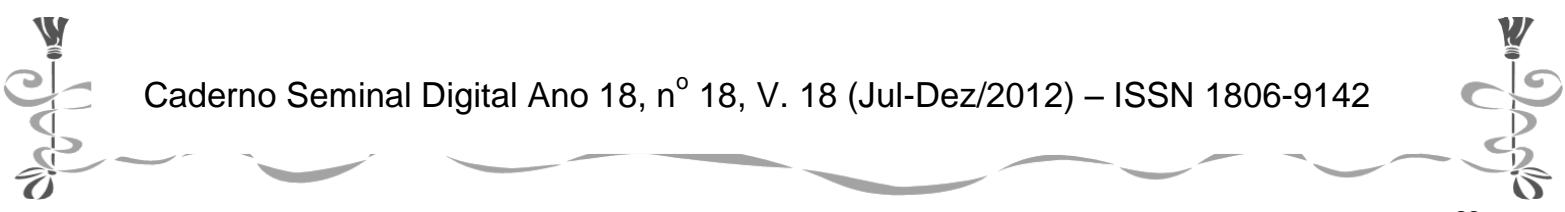




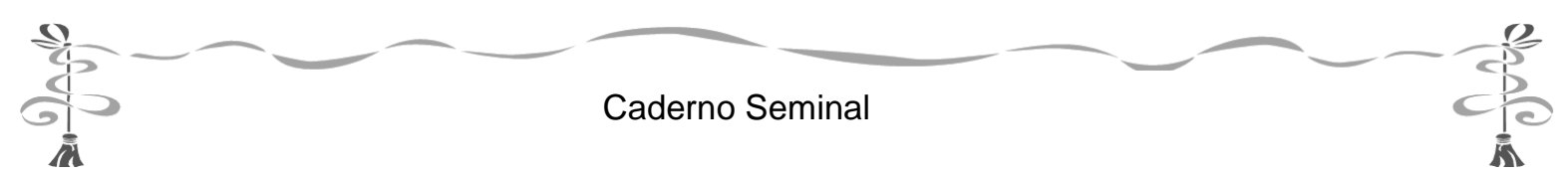

as EI são grupos de lexias indecomponíveis, salvo numa perspectiva etimológica ou histórica. Em sincronia, pela análise distribucional ou funcional, tais grupos formam uma unidade lexical (unidade à qual corresponde um só significado). Deveriam, portanto, constituir entradas específicas nos dicionários, o que, infelizmente, não ocorre.

Por outro lado, há outro inconveniente para se localizar num dicionário uma EI: qual o critério, seguro e único, para distinguir um termo de uma expressão e não outro como palavra-chave e, então, no verbete referente a esse termo, encontrar tal idiomatismo?

Uma constatação semelhante é feita por Caramori (2006, pp. 50 e 53):

constatou-se em tais obras, principalmente nas de língua portuguesa, uma grande irregularidade nos critérios de seleção das expressões. Câmara Cascudo, por exemplo, inicia o prefácio da $1^{\text {a }}$ edição de 1970 de Locuções Tradicionais no Brasil com a seguinte frase: "Todas as locuções reunidas neste livro foram ouvidas por mim". Os dicionários bilíngues de língua geral apresentam as expressões distribuídas de maneira não uniforme (alguns verbetes apresentam muitas, outros, muito poucas). (...) [Além disso,] uma breve análise dos dicionários bilíngues mais prestigiados e utilizados no Brasil comprova como as expressões possuem, nessas obras tratamento irregular.

Partindo de observações similares, Rodrigues (2009, p. 3) argumenta em favor da elaboração de dicionários especializados, como meio de "proporcionar ao estudante o desenvolvimento de competências que, muitas vezes, o próprio dicionário geral não pode [proporcionar]".

A resposta a essas questões é dada por Xatara (2001, p. 2), ao decidir utilizar, no seu Dicionário de expressões idiomáticas francês-português/português-francês uma

classificação alfabético-semasiológica das EIs, desconsiderando a classificação que repousa na noção de palavra-chave, para que o usuário não tenha que adivinhar ou se prender à lógica do dicionarista, o qual pode atribuir à palavra-chave o componente mais raro ou menos frequente ou determiná-la segundo uma hierarquia de categorias gramaticais (primeiramente o substantivo, depois o adjetivo, o advérbio e o verbo).

Embora tais questões sejam extremamente interessantes e relevantes, não estenderemos aqui nossos comentários sobre o tratamento das expressões idiomáticas pela lexicografia, na medida em que o aprofundamento dessa problemática foge ao escopo deste trabalho. Consideramos importante assinalar, todavia, que a quase inexistência e/ou a insuficiência de dicionários especializados ${ }^{28}$

${ }^{28}$ Exceção feita, evidentemente, do Dictionnaire de Xatara, que, como indicado, contempla unicamente o Português do Brasil e o Francês da França.

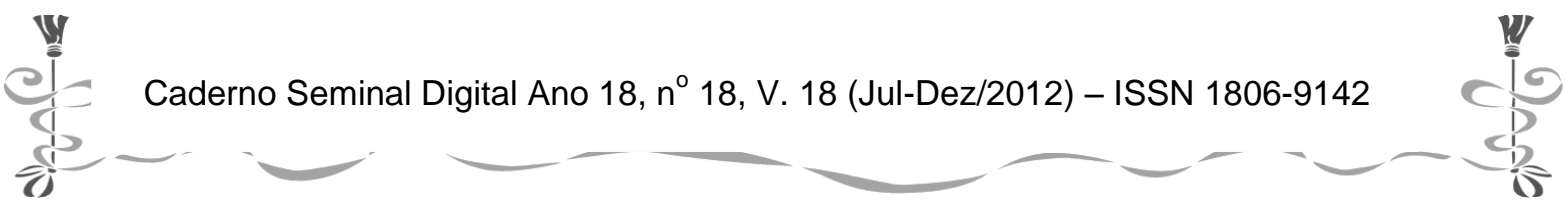




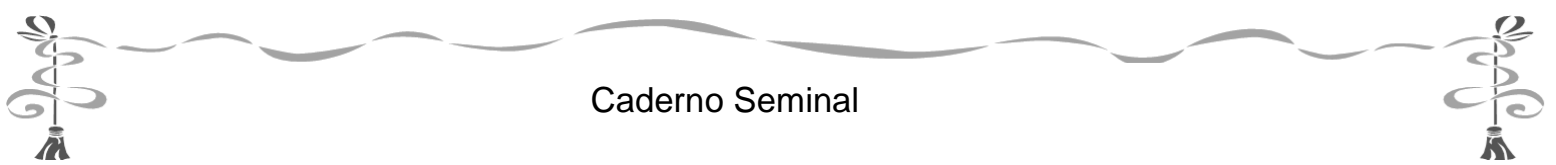

- sejam unilíngues, bilíngues, ou multilíngues -, aliadas ao tratamento geralmente precário da questão pelos dicionários gerais, incitam o tradutor a lançar mão de estratégias como as sugeridas por Tagnin, baseado no seu conhecimento das línguas e das culturas de partida e de chegada e na sua intimidade com elas (ver mais adiante). É por esta razão que, no que segue, trataremos mais especificamente de questões relacionadas ao ensino.

\section{O Lugar das El no Ensino de Línguas}

Como se poderia esperar, é possível observar que o ensino do léxico em geral - e das EI em particular - acompanhou e refletiu a evolução das concepções teóricas sobre o ensino de línguas e, mais especificamente, sobre o ensino de línguas estrangeiras, os progressos da linguística geral, da psicolinguística e da sociolinguística tendo uma repercussão bastante tênue e lenta sobre os métodos e concepções de ensino. Sendo assim, para os primeiros métodos de ensino de língua (materna ou estrangeira), que adotavam uma perspectiva eminentemente normativa, as EI não constituíam um objeto de atenção, na medida em que, como indicado acima, eram consideradas fenômenos marginais, pertencentes à fala (parole), e na medida em que, ao mesmo tempo, os fatos semânticos, discursivos e pragmáticos se encontravam igualmente marginalizados. Como se sabe, o ensino e a aprendizagem das línguas privilegiavam o estudo dos clássicos literários.

A partir dos anos 40 e até os anos 60, prevalecem as concepções behavioristas: os métodos de ensino são, portanto, predominantemente (i) comportamentalistas, do ponto de vista psicológico; (ii) audiolinguais, do ponto de vista pedagógico; e (iii) estruturalistas, do ponto de vista linguístico. É nesse contexto que os computadores e os laboratórios de línguas são introduzidos como instrumentos de ensino/aprendizagem, tendo o seu uso orientado pela repetição, imitação e aquisição de hábitos desejáveis. Também nessa concepção de ensino de línguas não há muito espaço para o tratamento das EI, uma vez que o processo de ensino/aprendizagem é tratado a partir de uma perspectiva mecanicista e comportamental.

Os anos 70-80 vêem a prevalência da abordagem comunicativa, isto é, a linguagem passa a ser vista como um instrumento de comunicação. Embora nessa abordagem do ensino/aprendizagem de línguas os conteúdos programáticos se baseiem numa concepção nocional-funcional, e o próprio processo de ensino/aprendizagem seja visto de maneira mentalista-cognitivista,

a competência estratégica dos falantes-ouvintes continua tropeçando num dogmatismo doutrinário que deixa várias lacunas no ensino do léxico.

São problemas fundamentais, relativos à compatibilização da visão de língua (a ser ensinada/aprendida) como discurso, à seleção do material lexical pertencente a cada fase de aquisição dessa língua, e aos meios

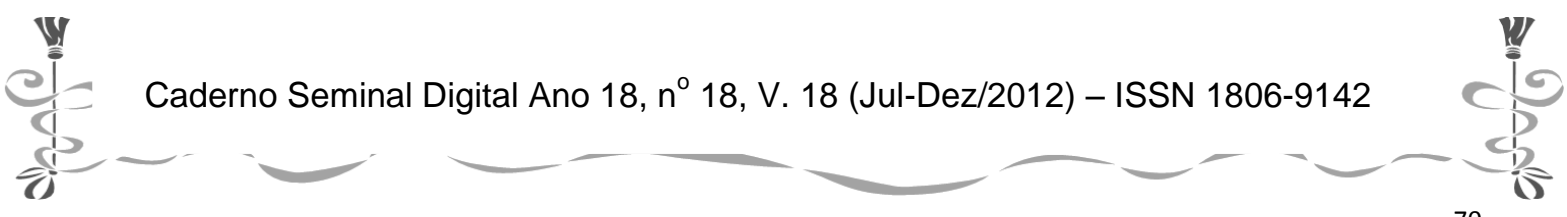




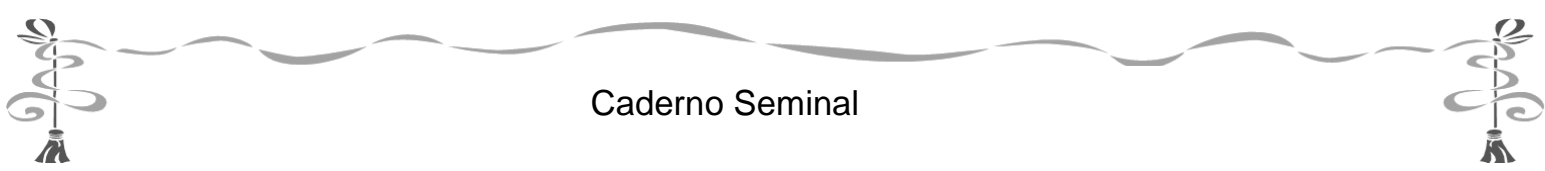

adequados para permitir aos alunos a interiorização das coerções semântico-sintáticas em língua e em discurso. Dentre esses problemas, aparece a questão dos idiomatismos (Xatara, 1995, p. 199).

Apesar de o estudo da semântica ter deixado de ocupar a posição secundária que até então ocupava, este ainda não é o caso do estudo das EI, mesmo se este constitui uma das maiores dificuldades no domínio de uma língua estrangeira, por ser o meio pelo qual se tem acesso à visão de mundo própria a cada cultura: é por essa razão que as EI levam mais tempo a ser adquiridas do que o restante do léxico. Lembremos, ainda, que, para dominar as EI, um aprendiz deve "memorizar um grande repertório de formas cristalizadas, conhecer o seu significado metafórico e saber adequá-las a contextos específicos" (id., ibid.).

A abordagem comunicativa do ensino de línguas deu origem à concepção interacionista, segundo a qual as bases da aprendizagem de uma língua são a interação com outros falantes e a negociação dos significados em situações reais de comunicação. $\mathrm{Na}$ abordagem interacionista, o erro deixa de ser visto como um empecilho a ser evitado a todo custo, passando a ser concebido como parte integrante e essencial da aprendizagem. Podemos notar, a partir daí, uma mudança de paradigma no ensino/aprendizagem de línguas, pois o seu objetivo passa a ser a aquisição da competência interativa, isto é, da capacidade de utilizar a língua de maneira autônoma e apropriada às diferentes situações de interação, com falantes reais. Do nosso ponto de vista, essa é a perspectiva que permite o tratamento adequado das EI no ensino/aprendizagem de línguas estrangeiras.

Antes, no entanto, de apresentar a nossa proposta de tratamento das EI no ensino/aprendizagem da tradução, faremos um exame da proposta de análise e classificação dessas expressões de Gonçalves \& Sabino (2001), que utilizam uma perspectiva contrastiva português-italiano.

\section{A Proposta de Gonçalves \& Sabino (2001)}

Ao tratar das EI em português e em italiano, Gonçalves \& Sabino (2001, pp. 68-73) propõem que sejam classificadas com base nos critérios de identidade, semelhança e diferença ${ }^{29}$ dos signos motivadores das metáforas, o que resulta em quatro grandes grupos, como resumido e exemplificado na Tabela 1, a seguir:

${ }^{29}$ Para tanto, baseiam-se nos critérios propostos por Steinberg (1985) para os provérbios.

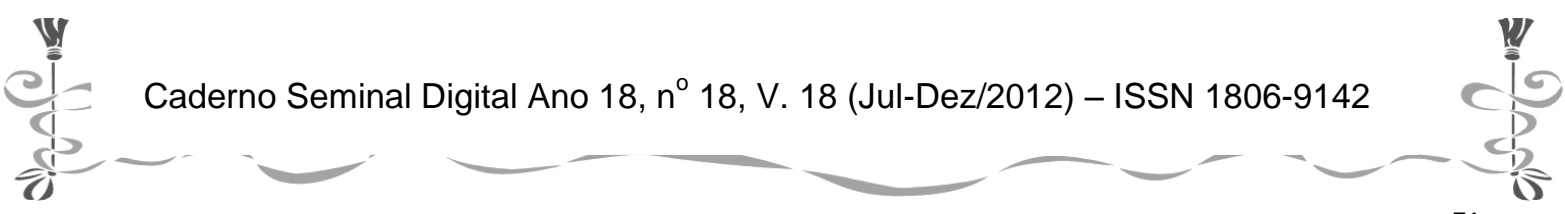




\section{Caderno Seminal}

\begin{tabular}{|c|c|c|}
\hline $\begin{array}{l}\text { El cujos signos motivadores } \\
\text { das metáforas são idênticos }\end{array}$ & $\begin{array}{c}\text { El cujos signos motivadores } \\
\text { das metáforas são } \\
\text { semelhantes }\end{array}$ & $\begin{array}{l}\text { El cujos signos motivadores } \\
\text { das metáforas são diferentes }\end{array}$ \\
\hline \multicolumn{3}{|c|}{ El morfossintaticamente idênticas ${ }^{30}$} \\
\hline Mostrate i denti & Mangiare quanto un grillo & Prendere fischi per fiaschi \\
\hline$\downarrow$ & $\downarrow$ & $\downarrow$ \\
\hline Mostrar os dentes & Comer como um passarinho & Confundir alhos com bugalhos \\
\hline \multicolumn{3}{|c|}{ El morfossintaticamente semelhantes ${ }^{31}$} \\
\hline Non aprir becco & Esserci quattro gatti & Imbarcare in un brutto affare \\
\hline$\downarrow$ & $\downarrow$ & $\downarrow$ \\
\hline Não abrir o bico & $\begin{array}{c}\text { Ter meia dúzia de gatos } \\
\text { pingados }\end{array}$ & $\begin{array}{l}\text { Entrar/embarcar num (a) } \\
\text { barco/ canoa furado (a) }\end{array}$ \\
\hline
\end{tabular}

\begin{tabular}{c|c|c|}
\hline Far rizzare i capelli & Giocare a carte scoperte & Fare l'indiano \\
$\downarrow$ & $\downarrow$ & $\downarrow$ \\
Deixar o cabelo em pé/ & Pôr as cartas na mesa & Dar uma de João-sem-braço \\
Ficar com o cabelo em pé & \\
\hline \multicolumn{2}{|c|}{ El sem um equivalente preciso na língua de chegada } \\
\hline \multicolumn{2}{|c|}{}
\end{tabular}

TABELA 1: CLASSIFICAÇÃO DAS EI SEGUNDO GONÇALVES \& SABINO (2001)

Embora interessante, essa proposta apresenta pelo menos dois inconvenientes. O primeiro deles é a não definição do conceito de signo motivador da metáfora e a não definição de critérios seguros para a sua determinação. Por exemplo, voltando aos exemplos da Tabela 1, podemos perguntar-nos por que o par Giocare a carte scoperte/Pôr as cartas na mesa pertence à segunda categoria ("EI cujos signos motivadores das metáforas são semelhantes") e não à primeira ("EI cujos signos motivadores das metáforas são idênticos"). Dito de outro modo: qual é "signo motivador da metáfora" escolhido pelas autoras, e que critérios determinam essa escolha? As mesmas perguntas podem ser feitas com relação ao par Mangiare quanto

\footnotetext{
30 "Aquelas que possuem morfologia e sintaxe idêntica em ambas as línguas" (op. cit., p. 68).

31 "Aquelas que possuem morfologia e sintaxe parecidas (semelhantes) em ambas as línguas" (op. cit., p. 70).

32 "Aquelas que possuem morfologia e sintaxe diferentes, em ambas as línguas" (op. cit., p. 71).
}

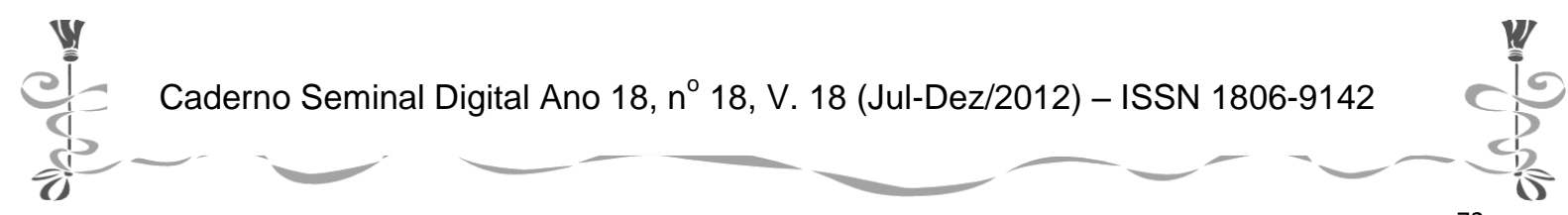




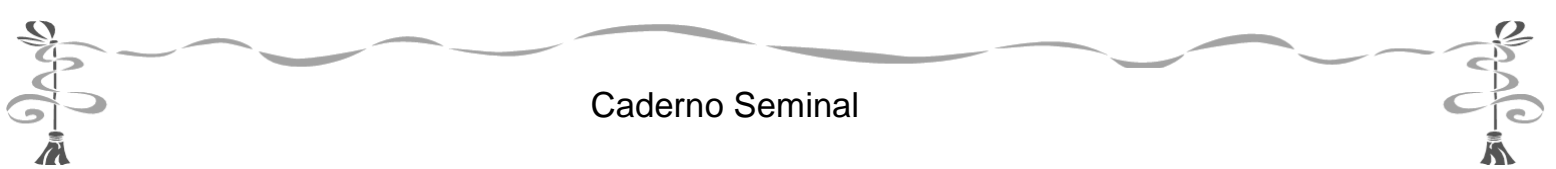

un grillo/Comer como um passarinho: tendo em vista a sua classificação na segunda categoria, podemos deduzir que o "signo motivador da metáfora" é o substantivo (grillo/passarinho). Mas por que razão não poderia ser o verbo (mangiare/comer)? Se fosse o caso, essa EI seria classificada como pertencente à primeira categoria. $\mathrm{O}$ problema da utilização desse tipo de critério, portanto, é que ele deixa margem a dúvidas que não podem ser resolvidas, bem como a interpretações sobre as quais não se pode afirmar com segurança que são corretas. Nesse sentido, o conceito de signo motivador da metáfora parece ser bastante semelhante à noção (utilizada por muitos autores) de palavra-chave, noção esta que provoca os problemas apontados por Xatara (2001, p. 2) com relação à inclusão das EI em dicionários:

Por exemplo, para localizarmos laisser passer l'eau sous le pont (deixar correr o marfim), poderíamos procurá-la sob a entrada de um substantivo (ean ou pont?) ou sob a entrada do componente de menor frequência (seria sous?). Mas qual consideração impõe ao lexicógrafo a escolha segura dessa ou daquela palavra-chave?

O segundo inconveniente da proposta de Gonçalves \& Sabino está relacionado à própria ideia de utilizar critérios morfossintáticos para a classificação das EI: não somente esses critérios levam a uma descrição pouco elegante, já que extremamente extensa e "pesada", mas, principalmente, essa classificação não nos ensina muita coisa a respeito da correspondência ou não das EI entre as duas línguas - embora o critério semântico-discursivo esteja subjacente à noção de signo motivador da metáfora e à noção de equivalência, que se mostra, afinal, ser o critério utilizado para os agrupamentos propostos (veja-se o quarto grupo: "EI sem equivalente").

No entanto, a eleição do critério morfossintático como determinante para a categorização proposta leva as autoras a examinar minúcias que não são úteis nem à descrição nem à aprendizagem das EI nas línguas estudadas. Isso fica mais claro quando da análise das EI semelhantes e das EI diferentes do ponto de vista morfossintático, que resumimos na Tabela $2^{33}$ :

\section{El morfossintaticamente semelhantes}

El cujos signos motivadores são idênticos

\begin{tabular}{c|c|c|c|c|c|c}
\hline Far & venire & - & l' & acqua/acquolina & in & bocca \\
\hline Dar & - & - & - & água & na & boca \\
\hline Fazer & ficar & com & - & água & na & boca \\
\hline
\end{tabular}

El cujos signos motivadores são semelhantes

${ }^{33}$ Exemplos extraídos das pp. 70-73.

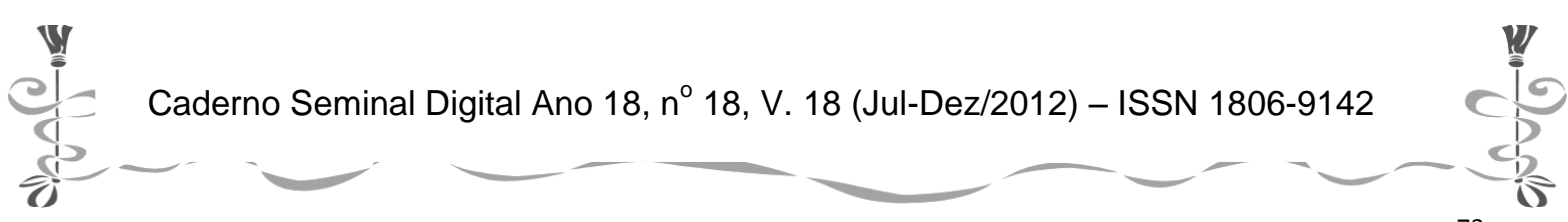




\section{Caderno Seminal}

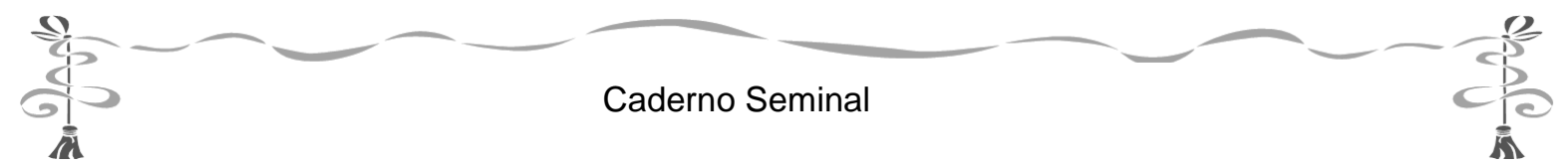

\begin{tabular}{c|c|c|c|c|c|c} 
Dare/fare & una & lavata & di & capo/testa & a & qualcuno \\
\hline Dar & uma & lavada & - & - & em & alguém \\
\hline Passar & um & sabão & - & - & em & alguém \\
\hline
\end{tabular}

El cujos signos motivadores são diferentes

\begin{tabular}{c|c|c|c|c}
\hline Essere & fatto & con & l' accetta & - \\
\hline Ser & feito & com & cuspe \\
\hline
\end{tabular}

El morfossintaticamente diferentes

El cujos signos motivadores são idênticos

\begin{tabular}{c|c|c|c|c|c|c}
\hline Non torcere & - & un & - & capello & a & qualcuno \\
\hline Não tocar & em & um & fio de & cabelo & de & alguém \\
\hline \multicolumn{7}{c}{ El cujos signos motivadores são semelhantes } \\
\hline
\end{tabular}

\begin{tabular}{c|c|c|c|c|c|c}
\hline Avere & la & bocca & che & puzza & di & latte \\
\hline Estar (ainda) & - & - & - & cheirando & a & leite \\
\hline
\end{tabular}

El cujos signos motivadores são diferentes

\begin{tabular}{c|c|c|c}
\hline Essere & come & mamma l' ha & fatto \\
\hline Estar & como & veio ao & mundo \\
\hline Estar & como & & nasceu
\end{tabular}

TABELA 2: ANÁLISE DAS EI MORFOSSINTATICAMENTE SEMELHANTES E MORFOSSINTATICAMENTE DIFERENTES SEGUNDO GONÇALVES \& SABINO (2001)

Indo um pouco mais longe, podemos dizer que a escolha do critério morfossintático para a descrição e a análise das EI provoca efeitos indesejáveis, na medida em que dá a entender que categorias gramaticais diferentes são comparáveis ou equivalentes. Observe-se, para tanto, o par Essere come mamma l'ha fatto/Estar como veio ao mundo/nasceu, além do par abaixo (op. cit., p. 73):

(3)

$\begin{array}{lllll}\text { Sapere } & \text { qualcosa } & \text { come } & l^{\prime} & \text { avemaria } \\ \text { Saber algo } & \text { decor } & e & \text { salteado }\end{array}$

Caderno Seminal Digital Ano 18, n 18, V. 18 (Jul-Dez/2012) - ISSN 1806-9142 


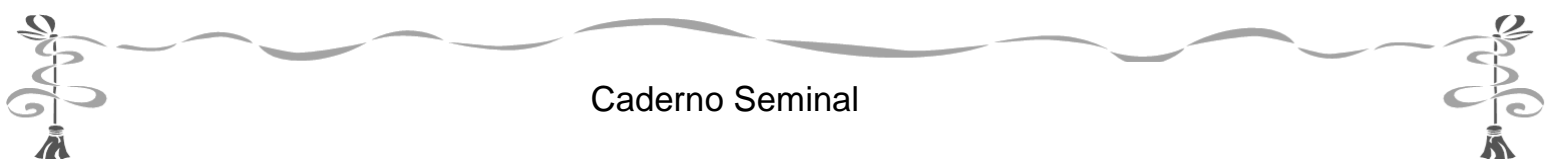

De modo semelhante, esse tipo de critério não permite observar - em todo o caso, as autoras não chamam a atenção para - o fato de que, em certos casos, o que se tem é uma simples troca de posição dos constituintes, como exemplificado pelo par abaixo (idem, p. 71):

(4)

$\begin{array}{llllll}\text { Mettere } & \text { fuori } & \text { le } & \text { unghie } & & \text { - } \\ \text { Pôr } & - & \text { as } & \text { garras de } & \text { fora }\end{array}$

De acordo com as autoras,

\begin{abstract}
obviamente não estamos pensando, e muito menos sugerindo, que [estas quatro relações possíveis, presentes na análise contrastiva das expressões] fossem fielmente memorizadas pelos aprendizes e, depois, rigorosamente acionadas pela memória de cada um, na tentativa de encaixar, cada expressão, em uma das relações apontadas. Se fosse assim, essa estratégia, ao invés de simplificar a difícil tarefa daqueles que almejam obter o domínio das expressões idiomáticas, acabaria, indubitavelmente, tornando-a muito mais árdua e penosa.

Assim sendo, o objetivo desta análise contrastiva foi alertar o aprendiz sobre as igualdades, semelhanças, diferenças e falta de equivalência entre unidades lexicais (simples ou) complexas de duas (ou mais) línguas, de modo que, de posse desses instrumentos e baseado em suas experiências de aprender, o aprendiz consiga se valer de estratégias próprias que possam minimizar seus esforços, quando sua meta é obter o domínio das expressões idiomáticas da língua estrangeira (op. cit., p. 74, sublinhado pelas autoras).
\end{abstract}

No entanto, a sua análise, assim como a sua proposta de classificação, constitui, na realidade, uma demonstração de que tratamento das EI por qualquer método que as decomponha é um equívoco, já que se trata, por definição, de expressões indecomponiveis e cristalizadas - como, aliás, as próprias autoras indicam na introdução do seu trabalho (p. 62). É por essa razão que apresentaremos, a seguir, uma proposta de classificação das EI que se concentra nas suas condições de utilização, considerando-as na sua globalidade.

\title{
El, Tradução e Ensino: Nosso Ponto de Vista
}

Partindo do princípio de que o trabalho com as EI deve privilegiar, por um lado, os seus aspectos semânticos, pragmáticos e discursivos e, por outro, o ponto de vista do aprendiz, sugerimos que sejam sistematicamente postas em relação com as suas situações e condições de uso. Em outros termos, a pergunta a fazer não é tanto "o que significa a EI $x$ ?" ou "como se constitui a EI $x$ ?", mas, antes, "em que situações se utiliza a EI $x$ ?".

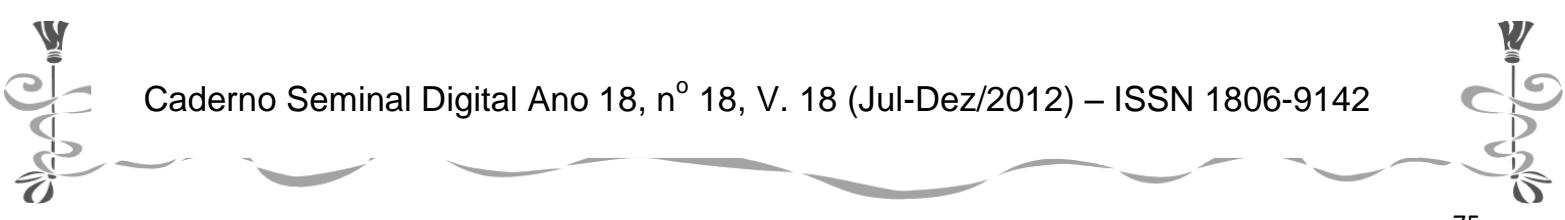




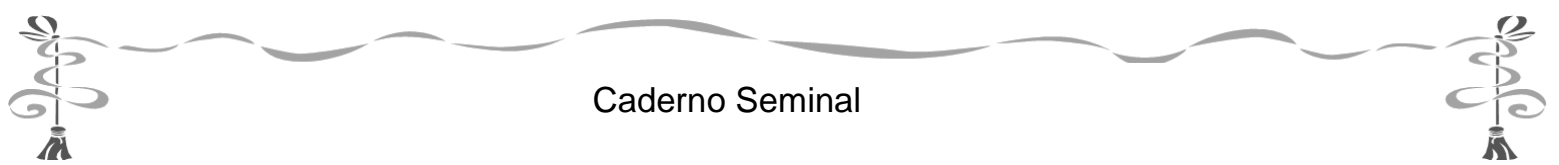

Evidentemente, também é importante levar em consideração a modalidade oral/escrita da língua, o registro, formal ou informal (assim como as diferentes combinações possíveis entre modalidade e registro), além, no caso da língua portuguesa, da variante, europeia ou brasileira ${ }^{34}$ - quer o português seja a língua de partida, quer seja a língua de chegada.

Com relação aos fatores modalidade e registro, cumpre observar, com Xatara (1995, p. 195), que as EI "fazem parte da linguagem comum de registro informal" e que elas

[se] encontram, em sua grande maioria, no nível coloquial (linguagem informal, que usa palavras novas, imagens pitorescas, sentidas como "anormalidades", sem que a frequência de seus desvios constitua uma deformação que torne "inaceitáveis" as mensagens dadas (...) (XATARA, 2001, p. 2).

Evidentemente, na medida em que os dois fatores em questão constituem contínuos e não domínios estanques, não se trata de classificar de maneira definitiva as EI, mas de indicar a sua esfera de atuação ou as suas tendências de utilização. Assim, podemos fazer observar, com relação à modalidade da língua e ao registro ${ }^{35}$, (i) que algumas são mais utilizadas em discursos orais informais - como, por exemplo, estar num mato sem cachorro ou avoir la dalle ${ }^{36}$-, ao passo que (ii) outras podem ser neutras ou não marcadas - como ser cabeça-de-vento ou donner un coup de main ${ }^{37}$-, (iii) outras, ainda, podendo pertencer a um registro vulgar ou chulo - como ter fogo no rabo ou péter plus haut que son $\mathrm{cu}^{38}$-, e que (iv) algumas poucas - como virar a casaca/tourner casaque ou prometer mundos e fundos/promettre monts et merveilles - podem ser utilizadas em discursos escritos formais. Com esses elementos em mãos, propomos que as EI sejam classificadas em quatro tipos:

\footnotetext{
${ }^{34} \mathrm{O}$ fato de mencionarmos unicamente as variantes europeia e brasileira do português não significa que sugerimos que as demais variantes sejam ignoradas. Evidentemente, na medida em que o professor domine outras variantes do português, esse conhecimento somente poderá enriquecer o trabalho com os alunos.

${ }^{35}$ A utilização da língua francesa a par da portuguesa, nos nossos exemplos, deve-se ao fato de a primeira ser a língua do país no qual trabalhamos e que utilizamos, portanto, quando se trata de comparar/contrastar estruturas com os nossos alunos.

36 "Morrer de fome".

37 "Dar uma mãozinha".

${ }^{38}$ Literalmente, "peidar mais alto do que o [seu] cu", isto é, "ser arrogante".
}

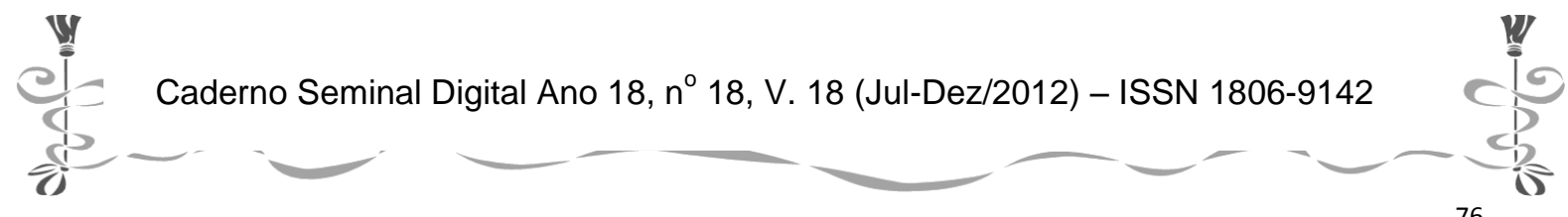




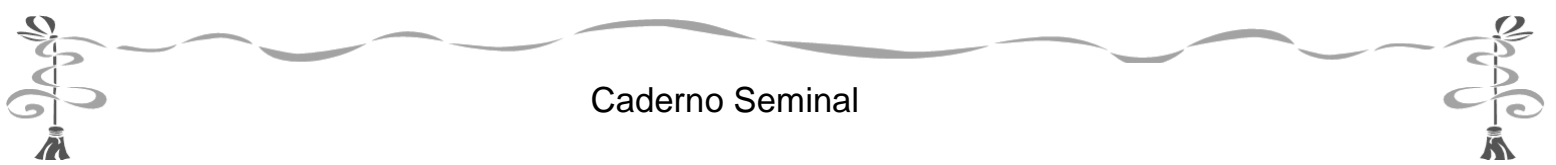

(i) El "idênticas", isto é, aquelas que têm mesma forma, mesmo sentido e, principalmente, mesmo uso (são utilizadas nas mesmas situações):

(5) Quand les poules auront des dents $\leftrightarrow$ Quando as galinhas tiverem dentes (PT) ${ }^{39}$

(6) Ser um homem feito $\leftrightarrow$ Être un homme fait

(7) Passar um sabão $\leftrightarrow$ Passer un savon

(8) Envoyer promener $\leftrightarrow$ Mandar passear

(9) Fourrer son nez $\leftrightarrow$ Meter o nariz

(10) La main droite ne sait pas ce que fait la main gauche $\leftrightarrow$ A mão direita não sabe o que a mão esquerda faz (BR)

(ii) El "parafraseáveis", isto é, diferentes quanto à forma, mas com mesmo sentido e, principalmente, mesmo uso (utilizadas nas mesmas situações):

(11) Château(x) en Espagne $\leftrightarrow$ Castelo(s) no ar

(12) Bater as botas/Esticar as canelas $\leftrightarrow$ Passer l'arme à gauche/Casser sa pipe

(13) Sant(inh)a do pau oco $\leftrightarrow$ Sainte-nitouche ${ }^{40}$

(14) Sair de fininho $\leftrightarrow$ Filer à l'anglaise

(15) Abrir o jogo $\leftrightarrow$ Jouer cartes sur table

(16) Quand les poules auront des dents $\leftrightarrow$ No dia de São Nunca

(17) Mettre son grain de sel $\leftrightarrow$ Meter o nariz

(18) Comer o pão que o diabo amassou $\rightarrow$ Manger de la vache enragée

(iii) El "reconhecíveis", isto é, que não têm um correspondente exato ou idêntico na outra língua, mas cujo sentido pode ser recuperado quando traduzidas ou adaptadas ${ }^{41}$ :

(19) Meter a colher $\rightarrow$ Mettre sa petite cuillère (cp. Mettre son grain de sel)

(20) Jogar merda no ventilador $\rightarrow$ Foutre la merde au ventilo ${ }^{42}$ (cp. Foutre la merde)

(21) La main droite ne sait pas ce que fait la main gauche $\rightarrow$ A mão direita não sabe o que faz a mão esquerda (PT)

(22) Filer un mauvais coton $\rightarrow$ Fiar um algodão ruim

(23) Ter pavio curto $\rightarrow$ Avoir la mèche courte (cp. Partir au quart de tour)

(iv) El "intradutíveis", isto é, que necessitam uma explicação ou explicitação:

\footnotetext{
${ }^{39}$ Nos exemplos, PT: norma portuguesa; BR: norma brasileira.

40 Note-se que a expressão francesa tem uma conotação eminentemente sexual, ao passo que a El em língua portuguesa pode ser utilizada em contextos em que essa conotação não está presente (indicando somente uma atitude/um comportamento considerado hipócrita). Mais precisamente, quando utilizada no masculino e sem o diminuitivo (santo do pau oco), essa El não apresenta conotações sexuais - que só aparecem, portanto, quando utilizada no feminino, o diminutivo parecendo reforçar essa conotação ou trazer uma nuance pejorativa. No entanto, mesmo no feminino acompanhado do diminutivo, a El em questão pode ser utilizada sem conotações sexuais: é o contexto mais amplo em que é utilizada, portanto, que permitirá decidir o valor a ser atribuído a sant(inh)a do pau oco.

${ }^{41}$ Observe-se que algumas dessas El poderiam ser incluídas na classe das "parafraseáveis".

${ }^{42}$ Ventilo é a forma familiar do termo ventilateur ("ventilador").
}

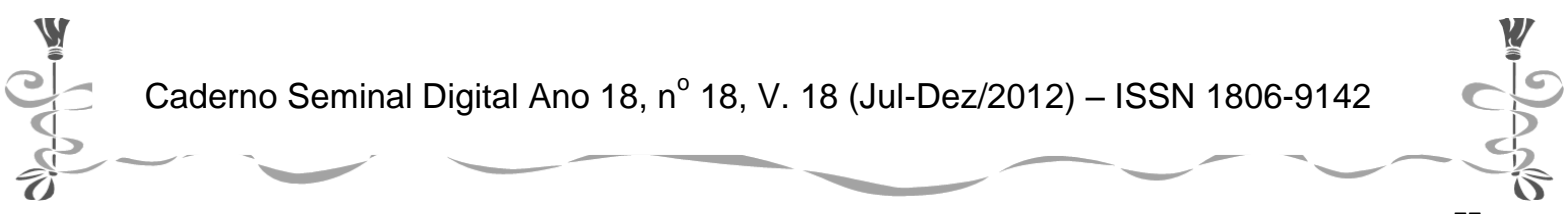




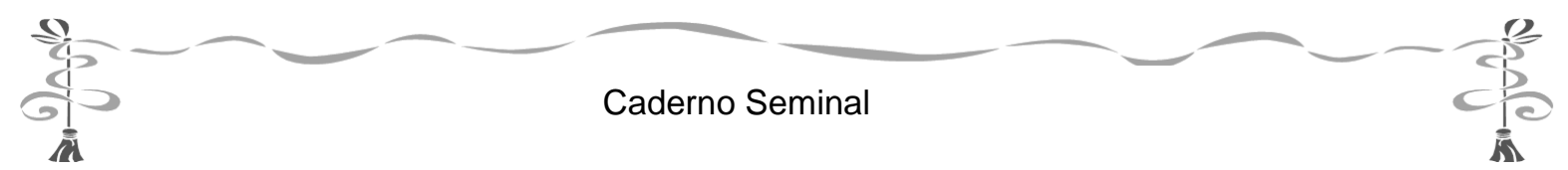

(24) Pôr uma pá de cal (BR) $\rightarrow$ Mettre une fin définitive

(25) Long comme un jour sans pain $\rightarrow$ Extremamente demorado

(26) Couler de source $\rightarrow$ Ocorrer naturalmente/logicamente

(27) Tirar o caval(inh)o da chuva $\rightarrow$ Abandonner ses illusions

(28) Broyer du noir $\rightarrow$ Ter pensamentos sombrios

Essa classificação das EI, feita principalmente em função das suas condições de utilização, permite pensar numa metodologia de ensino da sua tradução em quatro etapas: em primeiro lugar, é possível trabalhar, desde os níveis iniciais (A1-A2 do QECR ${ }^{43}$, por exemplo), as EI "idênticas" (aquelas que têm uma correspondência exata). Como observa Xatara (1995, p. 199), "ao menos em relação às línguas europeias, muitas EI se traduzem literalmente com o mesmo significado". Em segundo lugar, nos níveis "intermediários inferiores" (A2-B1 do QECR), é possível trabalhar as EI "parafraseáveis" (aquelas que compartilham as condições de uso). Em terceiro lugar, é possível trabalhar, nos níveis "intermediários superiores" (B1C1 do QECR), as EI "recuperáveis" (aquelas que podem ser traduzidas ou adaptadas), deixando para os últimos níveis (C1-C2 do QECR) o trabalho com as EI "intradutíveis" (aquelas que não têm correspondência). Cumpre observar que, a partir do segundo tipo (EI “parafraseáveis"), o professor começará a trabalhar sobre a utilização de estratégias de tradução, trabalho este que se acentuará à medida que aumentem o domínio e a autonomia da língua de chegada pelos alunos.

\section{Considerações Finais}

Como vimos, o estudo contrastivo das EI, fundamental para o ensino da tradução, deve pautar-se pelo estudo das suas condições de utilização nas línguas estudadas. Em outros termos, professores e alunos têm muito mais a ganhar ao dirigir o foco da sua atenção às situações que podem desencadear o emprego de uma EI do que ao estudar os seus constituintes. Evidentemente, um estudo morfossintático das EI é sempre possível, mas somente na medida em que permita observar que a morfossintaxe das EI não é diferente da morfossintaxe das formas livres.

No que diz respeito à sua aquisição, chamamos a atenção, com Fillmore (1979), para o fato de que esta se dá pela sua associação com as situações em que o seu uso é adequado, o que significa que, para a produção e a compreensão dessas expressões, embora necessária, a vinculação do léxico com a gramática - procedimento no qual se baseia mais comumente o ensino de línguas - não é suficiente, pois a sua interpretação, assim como o conhecimento do seu funcionamento e das suas funções "não são previsíveis por pessoas que apenas conhecem a gramática e o vocabulário de uma língua" (Xatara, 1995, p. 201). Como dissemos, o ensino da

${ }^{43}$ Quadro Europeu Comum de Referência para as Línguas. Ver Alves (2001).

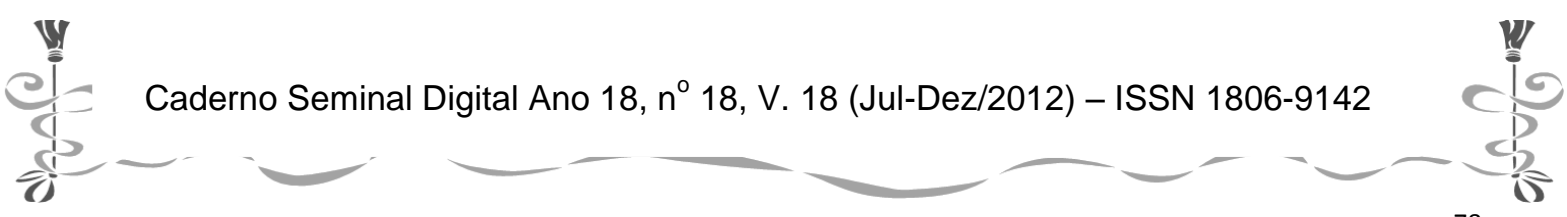




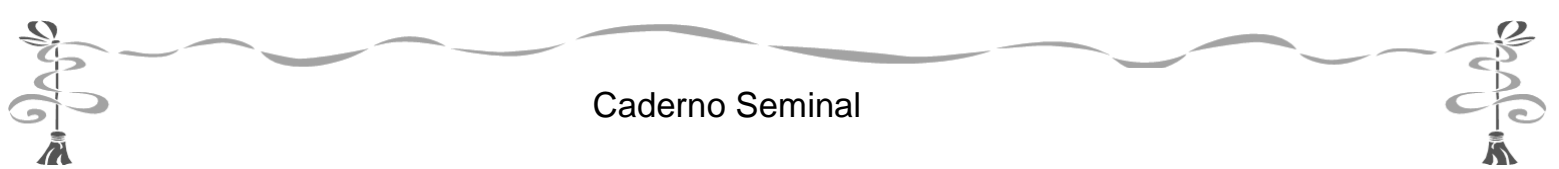

tradução das EI deve privilegiar (i) o ponto de vista do aprendiz e (ii) os aspectos semânticos, pragmáticos e discursivos envolvidos no seu uso.

Evidentemente, embora o tratamento dessas expressões pelos dicionários especializados ou gerais - ainda seja precário, não propomos que sejam abandonados. Como sublinha Reis (2008, p. 29), "os dicionários bilíngues trazem uma enumeração de equivalências que muitas vezes não satisfazem o consulente, principalmente na sua atividade de produção ou tradução. Isso se deve ao fato de que os equivalentes são dispostos fora de seus contextos de uso". No entanto, como essa mesma autora argumenta, "é impossível encontrar todas as traduções de todos os itens lexicais apropriados a determinado contexto de uso indicadas nos dicionários" (id., ibid.). Esta é mais uma razão para advogarmos em favor de um ensino que auxilie o aprendiz a se tornar um utilizador autônomo: pela percepção da correspondência entre as situações de enunciação, muito mais do que pela focalização da sua atenção nos elementos constituintes das EI.

Ao apresentar um sistema automático de ajuda à tradução, Wehrli (2004, p. 8, nossa tradução) sublinha a importância da "capacidade de reconhecer que um termo (...) pertence a uma expressão cristalizada ou a uma colocação, independentemente da ordem relativa ou da distância dos constituintes da expressão": desenvolver a autonomia dos alunos, futuros tradutores, significa, entre outras coisas, desenvolver justamente essa mesma capacidade.

Para concluir, cabe observar que a metodologia de ensino que preconizamos para as EI também pode ser empregada no trabalho com os provérbios, uma vez que estes também constituem um conjunto de formas (semi)cristalizadas - pelo menos do ponto de vista sincrônico - e que pertencem a um fundo cultural compartilhado pela comunidade dos falantes de uma dada língua (cf. Rocha, 1995). Cabe ressaltar, no entanto, como indica Caramori (2006, p. 49), que, diferentemente das EI, os provérbios têm "autonomia frástica completa".

Mas este é um tema para um outro trabalho.

\section{Referências}

ALVES, J. M. (dir.) (2001) Quadro Europeu Comum de Referência para as Línguas: Aprendizagem, Ensino, Avaliação. Lisboa: Asa. Disponível em http://sitio.dgidc.minedu.pt/recursos/Lists/Repositrio\%20Recursos2/Attachments/724/Quadro Europeu tot al.pdf. (acesso em 4.abr.2003).

BIDERMAN, M. T. C. (1978) Teoria linguística: linguística quantitativa e computacional. Rio de Janeiro: Livros Técnicos e Científicos.

CARAMORI, A. P. (2006) Expressões idiomáticas em Rodari: subsídios para a elaboração de um dicionário bilíngue (italiano-português). Tese de Doutorado. São Paulo: Universidade de São Paulo.

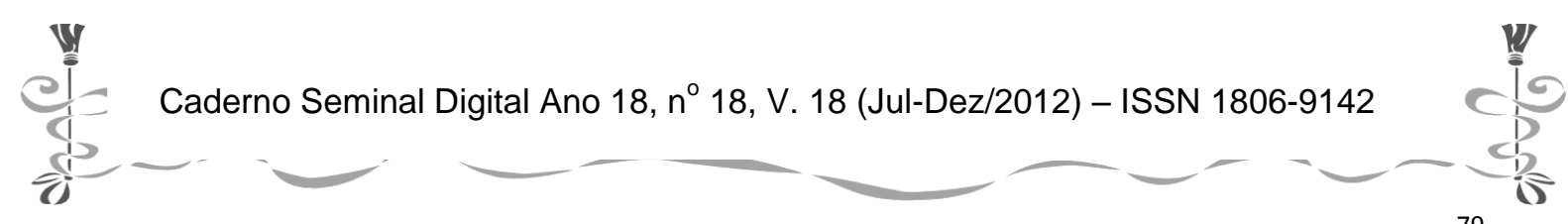




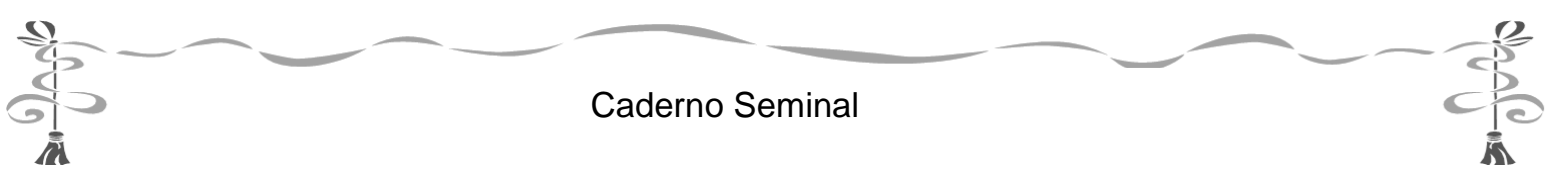

CHAFE, W. L. (1970) Meaning and the structure of language. Chicago/Londres: University of Chicago Press.

FILLMORE, C. J. (1979) “On fluency". In: FILLMORE, C. J. et al. (eds.) Individual differences in language ability and language behavior. New York: Academic Press, pp. 85101.

GONÇALVES, D. C. \& SABINO, M. A. (2001) "Desafios enfrentados para obter o domínio das expressões idiomáticas italianas". Fragmentos, $\mathrm{n}^{\circ}$ 21, pp. 61-76. http://www.periodicos.ufsc.br/index.php/fragmentos/article/viewFile/6540/6171. (acesso em 22.fev.2006).

MATIAS, L. C. (2008) Expressões idiomáticas corporais no Diccionario Bilingüe de uso españolportugués/português-espanhol (DiBU). Dissertação de Mestrado. Florianópolis: Universidade Federal de Santa Catarina.

REIS, S. R. N. (2008) Uma comparação do tratamento de expressões idiomáticas em quatro dicionários bilíngues francês/português e português/francês. Dissertação de Mestrado. Florianópolis: Universidade Federal de Santa Catarina.

RIVA, H. C. \& RIOS, T. H. C. (2002) "Correspondência idiomática intra e interlínguas". Revista Brasileira de Linguística Aplicada, $\mathrm{n}^{\circ}$ 2. Documento pdf, 8 páginas, disponível em http: L/www.letras.ufmg.br/rbla/2002 2/artigo7.pdf. (acesso em 30.mai.2009).

ROCHA, R. (1995) A enunciação dos provérbios: descrições em francês e em português. São Paulo: Annablume.

RODRIGUES, G. (2009) "Lexicografia e o ensino de expressões idiomáticas da língua portuguesa". Comunicação apresentada no VII GTLEX. São José do Rio Preto: Unesp, 16 a 18 de novembro. Resumo expandido disponível no formato pdf, 7 páginas, em http: //www.mel.ileel.ufu.br/gtlex/viiengtlex/pdf/resumos/Gislaine Rodrigues.pdf. (acesso em 31.out.2010).

SANTOS, L. (2011) "Algumas reflexões sobre o ensino de tradução: o caso das expressões idiomáticas”. In: TEIXEIRA, M., SILVA, I. \& SANTOS, L. (eds.) Novos Desafios no Ensino do Português, pp. 26-36. Santarém (Portugal): Escola Superior de Educação do Instituto Politécnico de Santarém (disponível em http: //calameo.com/read/0011572884243fe54043b; acesso em 9.nov.2011).

STEINBERG, M. (1985) 1001 provérbios em contraste. São Paulo: Ática.

TAGNIN, S. E. O. (1988) "A tradução dos idiomatismos culturais". Trabalhos em Linguística Aplicada, n 11 , pp.42-52. (1989) Expressões idiomáticas e convencionais. São Paulo: Ática.

WEHRLI, E. (2004) "Traduction, traduction de mots, traduction de phrases". TALN 2004, Fez (Marrocos), 19 a 21 de abril. Documento pdf, 9 páginas, disponível em http: //aune.lpl.univ-aix.fr/jep-taln04/proceed/actes/taln2004-Fez/Wehrli.pdf. (acesso em 13.jun.2006).

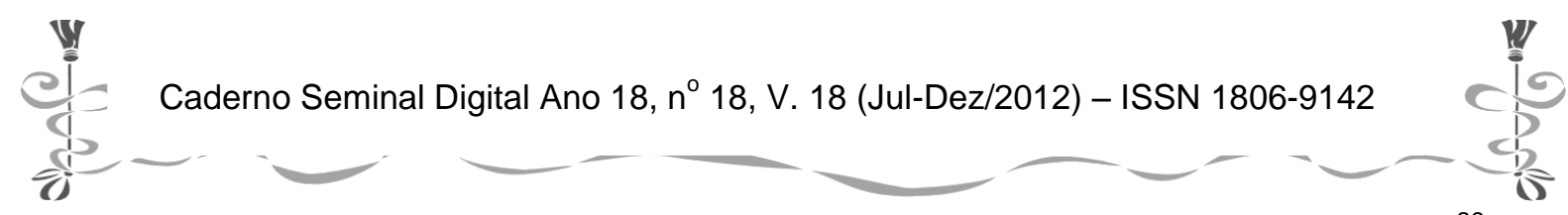




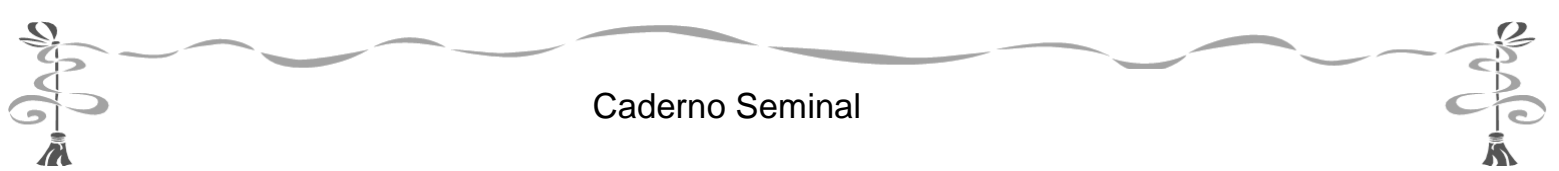

XATARA, C. M. (1988) “Os dicionários bilíngues e o problema da tradução". In: OLIVEIRA, A. M. P. P. de \& ISQUERDO, A. N. (orgs.). As ciências do léxico: lexicologia, lexicografia, terminologia. Campo Grande (MS): Ed. UFMS, p.179-86.

(1995) “O resgate das expressões idiomáticas”. Alfa, n 39, pp. 195-210.

. (1997) “A comparação nas expressões idiomáticas”. Alfa n 41, pp. 211-222.

- (2001) "Dicionário de expressões idiomáticas francês-português/portuguêsfrancês". Idioma, $\mathrm{n}^{\circ}$ 21. Documento Word, 4 páginas, disponível em http: //www.institutodeletras.uerj.br/igeral.html (acesso em 23/01/2005).

(2007) Dictionnaire électronique d'expressions idiomatiques français-portugais/portugais-français.

Nancy (França): ATILF/CNRS. Disponível nos endereços www.cnrtl.fr/dictionnaires/expressions idiomatiques/index pf.php (em português) e www.cnrtl.fr/dictionnaires/expressions idiomatiques (em francês) (acesso em 4/12/2009).

XATARA, C. M. \& OLIVEIRA, W. L. de (2002). Provérbios, idiomatismos e palavrões francêsportuguês e português-francês. São Paulo: Cultura Editores Associados.

Caderno Seminal Digital Ano 18, nº 18, V. 18 (Jul-Dez/2012) - ISSN 1806-9142

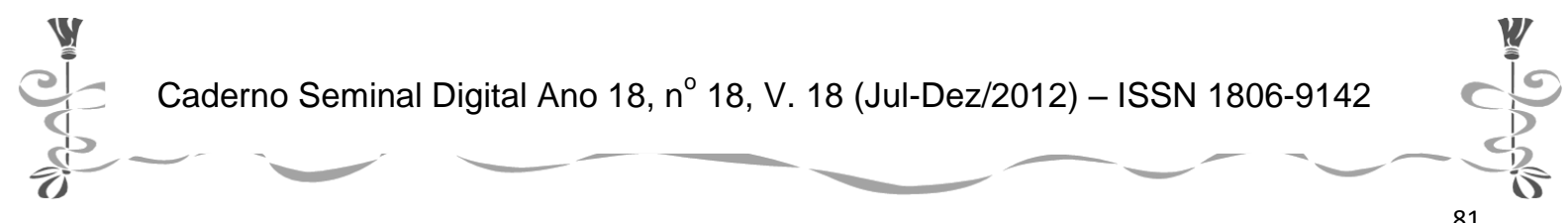

